\title{
Evaluation of Regional Economic Disparities in Beijing - Tianjin - Hebei Region based on Factor Analysis
}

\author{
Jian $\mathrm{Li}^{1,2}$, Juncen Guo ${ }^{1}$ \\ ${ }^{1}$ Research Center of Circular Economy and Enterprises Sustainable Development, Tianjin University \\ of Technology, Tianjin 300384, China \\ ${ }^{2}$ College of Management and Economics, Tianjin University, Tianjin 300072, China
}

Keywords: The Region of Beijing; Tianjin and Hebei; Regional Economic; Factor Analysis.

\begin{abstract}
The region of Beijing, Tianjin and Hebei is one of Chinese areas where regional economic development is special. This paper uses the factor analysis method to carry on the appraisal analysis to the regional economic development difference of Beijing-Tianjin-Hebei. Based on the comprehensive score of each city's economic development level obtained by the factor analysis method, the level of economic development of Beijing, Tianjin and Hebei was mapped to visually represent and analyze the differences of the economic development level of Beijing, Tianjin and Hebei in 2015.Based on the results of the model, we put forward the cooperative path on the economic development of Beijing, Tianjin and Hebei.
\end{abstract}

\section{Introduction}

Regional economic differences are the focus of regional economics research, but also the precondition and starting point for governments to formulate regional economic policies. Known as the Chinese economic locomotive, Beijing-Tianjin-Hebei region, the Yangtze River Delta region and the Pearl River Delta region are the three growth pole of the Chinese economy. But in comparison, the integration of the Beijing-Tianjin-Hebei region is not enough, and the phenomenon of fragmented economic development is very serious.In 2014, Xi Jinping proposed the coordinated development of Beijing, Tianjin and Hebei is a major national strategy, so the integration of Beijing-Tianjin-Hebei is up to the national strategic level. Therefore, a comprehensive and accurate discussion of regional economic disparities in Beijing, Tianjin and Hebei will be of great guiding significance for the implementation of the Beijing-Tianjin-Hebei integrated development strategy. This paper will use the factor analysis method to quantitatively study the spatial difference of regional economic development in Beijing, Tianjin and Hebei, and put forward the coordinated development path of regional economy in Beijing, Tianjin and Hebei.

\section{Data source and index selection}

The research object of this paper is the Beijing-Tianjin-Hebei area, which refers to the areas including 13 cities such as Beijing, Tianjin, Baoding, Langfang, Tangshan, Handan, Xingtai, Qinhuangdao, Cangzhou, Hengshui, Chengde, Zhangjiakou and Shijiazhuang. Data from the "Beijing Statistical Yearbook", "Tianjin Statistical Yearbook", "Statistical Yearbook of Hebei Province" and the city in 2015 the national economic and social development of statistical bulletins.

Therefore, this paper uses multiple indicators to evaluate the regional economic disparities in Beijing, Tianjin and Hebei. In order to ensure the availability of data and scientific indicators, this paper selects 5 indicators including the regional GDP $\left(X_{1}\right)$, public budget income $\left(X_{2}\right)$, fixed assets investment $\left(X_{3}\right)$,total retail sales of social consumer goods $\left(X_{4}\right)$, per capita disposable income of urban residents $\left(X_{5}\right)$, and use the factor analysis method to comprehensively evaluate the economic development level of each region. 


\section{Factor analysis}

Factor analysis is a prerequisite for the strong correlation between the variables, therefore, the correlation analysis of the indicators should be carried out to analyze whether the data obtained is suitable for factor analysis. In this paper, the KMO test and Bartlett test are to detect the correlation between the data obtained, and the results shown in Table 1.

Table 1. KMO and Bartlett test

\begin{tabular}{|c|c|c|}
\hline Sufficient sampling Kaiser-Meyer-Olkin was taken & & 0.667 \\
\hline Bartlett's Sphericity Test & Approximate chi-square & 113.665 \\
\hline & df & 10 \\
\hline & Sig. & 0.000 \\
\hline
\end{tabular}

From Table 1, the KMO value is 0.667, and the Bartlett's spherical test chi-square value is larger. The significant level is less than 0.01 , so the data obtained is suitable for factor analysis.

Using SPSS software to get the data to do factor analysis, factor cumulative variance contribution rate in Table 2.

Table 2. Cumulative variance contribution rate of factor

\begin{tabular}{|c|c|c|c|c|c|c|}
\hline \multirow{2}{*}{ Composition } & \multicolumn{4}{|c|}{ Initial eigenvalue } & \multicolumn{3}{c|}{ Rotate the square and load it } \\
\cline { 2 - 7 } & Total & Variance\% & Accumulation\% & Total & Variance\% & Accumulation\% \\
\hline 1 & 4.483 & 89.656 & 89.656 & 3.124 & 62.484 & 62.484 \\
\hline 2 & 0.417 & 8.335 & 97.991 & 1.775 & 35.507 & 97.991 \\
\hline 3 & 0.078 & 1.567 & 99.558 & & & \\
\hline 4 & 0.020 & 0.399 & 99.956 & & & \\
\hline 5 & 0.002 & 0.044 & 100.00 & & & \\
\hline
\end{tabular}

From Table 2, the cumulative contribution variance of the first two main factors is $97.991 \%$, more than $85 \%$. Therefore, two main factors are extracted, and the factor scores are calculated by regression method, and the factor contribution of each principal factor after rotation Rate of the cumulative contribution of the two main factors of the proportion of the weight to calculate the i-th area of the composite score, the calculation is as follows:

$$
F^{i}=0.6377 F_{1}^{i}+0.3623 F_{2}^{i}, i=1,2, \ldots, 13
$$

$F_{1}^{i}$ is the score of the $\mathrm{i}$-th region on the first principal factor and the score of the $\mathrm{i}$-th region on the second principal factor.

According to formula (1) to calculate the Beijing-Tianjin-Hebei regional economic development level of 13 cities integrated score. By the comprehensive score we can directly learn the Beijing-Tianjin-Hebei regional level of economic development level. The higher the comprehensive score, the higher the level of economic development of the city. If a city's comprehensive score is positive, then the city's economic development level is above the average level of the Beijing-Tianjin-Hebei regional economic development; if negative, then the city's economic development level is under the average level of the Beijing-Tianjin-Hebei regional economic development. According to the formula (1), the Beijing's comprehensive score is the highest, and it is 1.9647 followed by Tianjin with 1.0973. The highest score in Hebei is Tangshan, and it is 0.059.The lowest is Chengde, and it is -0.4618.The level of Beijing, Tianjin and Tangshan is above the average score of economic development in the Beijing-Tianjin-Hebei region. And the comprehensive scores of the three cities are very different. The comprehensive score of Beijing is nearly twice that of Tianjin. And the level of economic development in Beijing and Tianjin is far beyond the economic development of Tangshan. The level of economic development in the Beijing-Tianjin-Hebei region under the average level of economic development in 10 cities. Relative to Beijing, Tianjin, and the cities’ economic development level is relatively high backward. 


\section{Economic development level of the bitmap}

Based on the above study, we use the method of natural discontinuity to divide the economic development level of Beijing, Tianjin and Hebei into four grades. It should be noted that the Xianghe County, Langfang City, Hebei Province, is geographically surrounded by Beijing and Tianjin, and not connected to other areas of Langfang City. It can only be displayed as an independent area, so the economic development level of this area uses the comprehensive score of Langfang City. This approach is used in the following study.

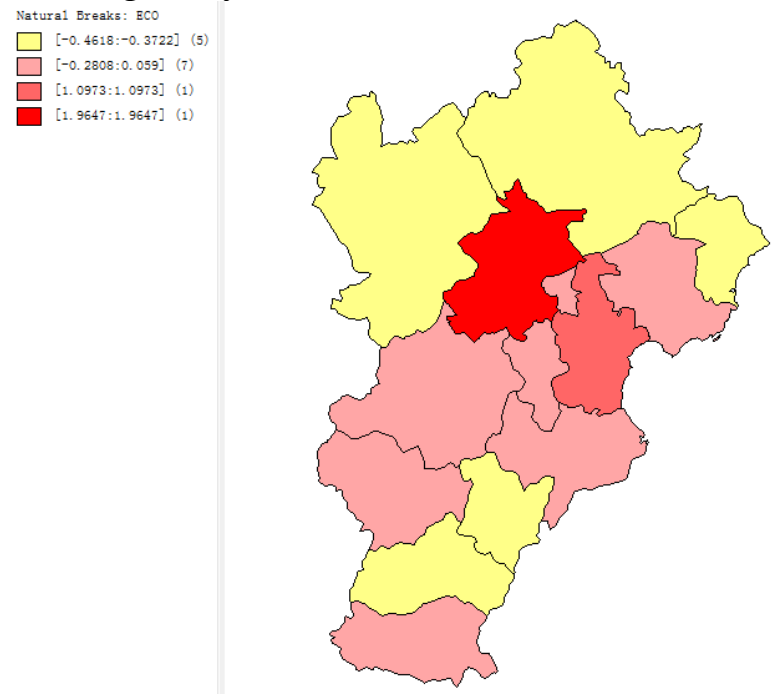

Fig.1 The bitmap of Beijing, Tianjin and Hebei economic development level in 2015

From the above analysis, there is a big gap between the cities, the economic development level among the cities in Hebei Province is relatively small. But in the region of the Beijing-Tianjin region, the economic development level of Beijing-Tianjin-Hebei region is extremely uneven. And it is a big difference, which seriously restricts the implementation of the Beijing-Tianjin-Hebei coordinated development strategy. Therefore, it is necessary to study this huge difference in the development of Beijing-Tianjin-Hebei region.

As shown in Figure 1, the highest level of economic development is Beijing, with the highest level of economic development in Beijing-Tianjin-Hebei region; the second level of economic development is at a high level in Tianjin; the third level includes Tangshan, Langfang, Baoding, Cangzhou, Shijiazhuang, Handan; the lowest grades include Qinhuangdao, Chengde, Zhangjiakou, Hengshui, Xingtai, the level of economic development of these cities is relatively backward.

Overall, the level of economic development between the cities of Beijing, Tianjin and Hebei is quite different. The economic development level of Beijing and Tianjin is relatively high, while the economy of each city in Hebei shows a relatively backward trend. If we cannot control and narrow this gap, it is bound to the Beijing-Tianjin-Hebei cooperation in the development of major strategies for the implementation of great resistance. In order to better control and reduce this difference, it is necessary to put forward the coordinated development path of regional economy in Beijing, Tianjin and Hebei.

\section{Policy suggestion}

From the above research results, we propose the following policy recommendations for the Beijing-Tianjin-Hebei co-development path:

First, the investment in fixed assets and industrial adjustment. Hebei Province should focus on upgrading the proportion of fixed assets investment in the secondary and tertiary industries, and enhance the degree of emphasis and investment in the secondary and tertiary industries. What's more, it should reduce the degree of emphasis on the primary industry and the proportion of investment in fixed assets, and transfer the fixed assets investment to the tertiary industry of investment and development. To make appropriate investment, investment in fixed assets should be coordinated with 
the local economic development, rational allocation of investment resources, and improve the efficiency of the use of resources to achieve the role of investment to promote economic growth to maximize. Since the development of Beijing and Tianjin in two or three industry is relatively mature, Beijing and Tianjin can transfer some of the industry for the development of Hebei Province. Hebei should undertake, so a certain amount of investment is also introduced in Hebei Province. Thus we will finish construction of the Beijing - Tianjin - Hebei economic coordinated development. In the future development, we should gradually adjust the industrial structure, according to the needs of economic development, promote the rationalization of industrial structure, and promote the healthy development of regional economy in Beijing, Tianjin and Hebei.

Second, industrial development. Industry has always been an important support for the economic development of Beijing, Tianjin and Hebei. Industrial division of labor and cooperation are the important contents of regional economic development. Beijing's industrial industry should transfer to Tianjin and Hebei. In the process of industrial transfer, it is necessary to consider the existing industrial bases of the three places, and also to combine the functions of cities to make the industrial transfer more rational, scientific and sustainability. Hebei plays the role of undertaking the transformation of Beijing-Tianjin science and technology. In the process of industrial transfer, it should give full play to its advantages and highlight its features. It should also take into account the dual roles of Beijing and Tianjin and develop their own roles, so as to select the industries they want to undertake taking into account the regional strategic industrial chain construction.

Third, the size of the market. The higher population density is conducive to increasing the market. The market enlargement is beneficial to the development of the enterprise, and it will promote the economic development of the region. Therefore, adjusting the population of Beijing-Tianjin-Hebei region is of great significance. We must strengthen the equalization of Beijing, Tianjin and Hebei basic public services and ease the population. What's more, it is necessary to optimize the pattern of resources and industrial distribution, and promote the rationalization of the population distribution of the Beijing-Tianjin-Hebei region.

\section{Conclusion}

In this paper, we use the factor analysis method to explore the regional economic development level of Beijing, Tianjin and Hebei. The economic development level of Beijing, Tianjin and Hebei is analyzed. The result shows that the level of economic development in Beijing, Tianjin and Hebei is very uneven. The economic development level of Beijing and Tianjin is high, while the economy of the cities of Hebei Province has shown a relatively backward trend. Based on this, the coordinated development path of Beijing-Tianjin-Hebei economy is put forward from three aspects: industrial adjustment, industrial development and market scale.

\section{References}

[1] Siguret V, Gouin-Thibault I, Gaussem P, et al. The Impact of Fiscal Policy on the Regional Economy: Evidence from South Sulawesi, Indonesia [J]. Journal of Applied Sciences Research, 2013, 273(3):644-650.

[2] Batabyal, Amitrajeet A, Nijkamp P. Asymmetrie Information, Entrepreneurial Activity, and the Scope of Fiscal Policy in an Open Regional Economy [J]. International Regional Science Review, 2010, 33(4):421-436.

[3] Lee G K, Blakeslee L L, Butcher W R. Effects of Exogenous Price Changes on a Regional Economy: An Input-Output Analysis [J]. International Regional Science Review, 1977, 2(1):15-27.

[4] Willamson J G. Regional Inequality and the Process of National Development: A Description of the Patterns [J].Economic Development and Cultural Change,1965,13(1):3-45.

[5] Friedman J. Regional Development Policy [M].Cambridge: MIT Press,1996.

[6] Demberger R F. China's Development Experience in Comparative Perspective [M]. Cambridge University Press, 1980. 